\title{
Feasibility Study for a Neutron-Based Investigation of Polymer Cement Concretes
}

\author{
Massimo Rogante ${ }^{1, *}$, Irina K. Domanskaya ${ }^{2}$, Ekaterina S. Gerasimova ${ }^{2}$, Elena Vladimkrova ${ }^{2}$ \\ ${ }^{1}$ Rogante Engineering Office, Contrada San Michele 61, 62012 Civitanova Marche, Italy \\ ${ }^{2}$ Ural Federal University, 19, Mira Str., 620002 Yekaterinburg, Russian Federation \\ *Corresponding Author: main@roganteengineering.it
}

Copyright (C) 2013 Horizon Research Publishing All rights reserved.

\begin{abstract}
Study of dense cements, ceramics and related materials such as cement stones, is significant to create novel advanced components for various types of buildings and structures. These materials can possess high functional properties and they can be adopted for various purposes, for instance as corrosion resistive coatings for cement constructions. In this paper, the investigability of polymer cement concretes by neutron beam techniques (NBT) and, in particular, the nano-scale characterization by small angle neutron scattering (SANS) of polymer cement concrete (PCC) samples made of Portland or aluminous cement with added $\gamma \mathrm{Al}_{2} \mathrm{O}_{3}$ and redispersible dry polymer, are discussed. The main aims are to assess key parameters (e.g., porosity, fractal dimensions, size distribution, presence of cracks or open and closed pores) responsible of the materials' performance at the scale from $1 \AA$ to $100 \AA$, as well as to expand the possibility of applications.

NBT, among the other non-destructive diagnostics, are particularly unique in the complete analysis of industrial materials when supplying essential information. The results obtained by means of a neutron-based investigation can translate into the optimization of consistency and the design of operating conditions and procedures that support and enhance quality and safety levels. Various examples concerning the examinations of different kinds of cements are reported. This state-of-the-art stage indeed confirms the industrial applicability of NBT in completing the characterization of the considered materials.
\end{abstract}

Keywords Polymer Cement Concretes, Neutron Techniques, SANS, Industrial Applications, Porosity

\section{Introduction}

Conventional investigations of cements and artificial stones adopt classical methodologies to obtain information on aspects mainly related to macro and micro-structure, fatigue behaviour and computational mechanics. These investigations rely essentially on standard tests, theoretical studies and simulation-based analyses.

With regard to artificial stones, on the basis of the inorganic binding, it is important to study their structure, in particular the characteristics of pores, their size distribution and the phases' interface. Porosity, as a key parameter for cements, can affect mechanical and heat-insulation properties. This factor is usually assessed by means of gravimetric techniques, gas and liquid porosimetry (e.g., mercury intrusion porosimetry) and acoustic methods. An acoustic-electric technique has been studied, for instance, establishing the interrelation between porosity and the characteristics of electric and acoustic responses to their pulsed mechanical excitation [1]. The research on parameters such as hydration degree of binder, balance between crystalline and gel phases of formed hydrated compounds, morphology and sizes of crystal hydrates, is also essential. To study these parameters, different methods are normally adopted, in particular X-ray and differential thermal analysis, infrared spectroscopy, optical and electronic microscopy. Various studies are being carried out, moreover, exposing weathered materials to diverse stresses and conditions and using modal-based simulations; one of the main objectives is to obtain indication in order to predict the cement's behaviour after ageing.

It is clear that the development in diagnostics of these materials is directly dependent on the application of successful methods to evaluate ageing damages and other defects, in order to establish the relationship between their characteristics and macroscopic functional properties.

Nanoscale investigations of cement stones are very important to determine the interaction mechanisms. The study of cements and related materials seems to be fundamental, besides, to create novel advanced components with elevated functional properties such as hardness and durability (i.e., the cement's aptitude to resist the infiltration of liquid and oxygen), resistance to ageing, cracks' formation, stability of mechanical modules and ecological criteria. NBT are being progressively considered as effective non-destructive methods for exploring and modifying the internal nano features of materials throughout an extensive range of disciplines in engineering, chemistry, physics and 
medicine. These tools can represent a key answer, also in the present case, to the need for extending material life and preventing ageing-related degradation. Neutrons can reveal significant properties, allowing the assessment of responses to external influences over the specimen's entire volume [2, 3]. What differentiates NBT from other investigation tools is the capability to non-destructively capture information about the material's micro- and nano-physical structures down to $\sim 1 \AA(0.1 \mathrm{~nm})$ [2]. Preliminary SANS measurements on PCC samples have shown the suitability and the usefulness of adopting this technique. A full analysis of SANS results related to the considered investigated samples, following a complete data treatment of these results, will be the object of another dedicated paper. The present paper represents a feasibility study concerning neutron investigations of PCC in general, reporting also the state-of-the-art.

\section{Materials and Methods}

\subsection{Polymer Cement Concretes}

PCC and polymer cement mortar (PCM) are defined to be cement-based concrete (mortar) with the addition of various high-molecular compounds as aqueous dispersions. The addition of polymers allows changing the cement stone's structure towards the key direction [4-9]. Two active components can be considered, mineral binding agent and organic matter. The binding agent and water form the cement stone, which joints particles of aggregate together, to create a monolith. In the composite binding, material polymer component and mineral binder are selected to be efficiently combined and to show their advantages, while amplifying the strong points. During the removal of water from the concrete the polymer forms a thin layer on the surface of pores, cement and aggregate nodules, and this layer possesses a good adhesive behaviour.

The main requirement to the polymer addition is to retard the hardening process of cement stone with the least possible rate. Cement neo-formations generate the crystalline - coagulation structure; the rigid mineral skeleton formed strengthens in depressed defect points (pores and cracks) with polymer, leading to the creation of a composite material with improved strength and elasticity, owing to articulated joining of hydrates with more flexible particles, nets and films of strong elastic organic polymers that possess adhesiveness.

The concrete's main properties influenced by the addition of polymer are strength, abrasive resistance and deformability. Bending and tensile strength increases greatly and compressive strength is improved as well. Strength is one of the most important characteristics related to the structural properties of the material. Strength values, for such heterogeneous material as polymer cement, can be evaluated to determine the phase composition. Abrasive resistance increases notably with the enhancement of the polymer. The polymer acts as a binder that prevents tearing of the cement stone components from the surface. The elasticity modulus of concrete usually decreases by increasing the polymer/cement ratio.

A novel research carried out by the Department of Building Materials of the Ural Federal University (DBM-URFU) is devoted to finding out the interaction between cement, redispersible dry polymer and $\mathrm{Al}_{2} \mathrm{O}_{3}(\gamma$ type). Firstly, $\gamma-\mathrm{Al}_{2} \mathrm{O}_{3}$ is produced by thermal hydrolysis process [10]. Figure 1 shows a micro photo of $\gamma \mathrm{Al}_{2} \mathrm{O}_{3}$ obtained by aluminium chloride thermo-hydrolysis.

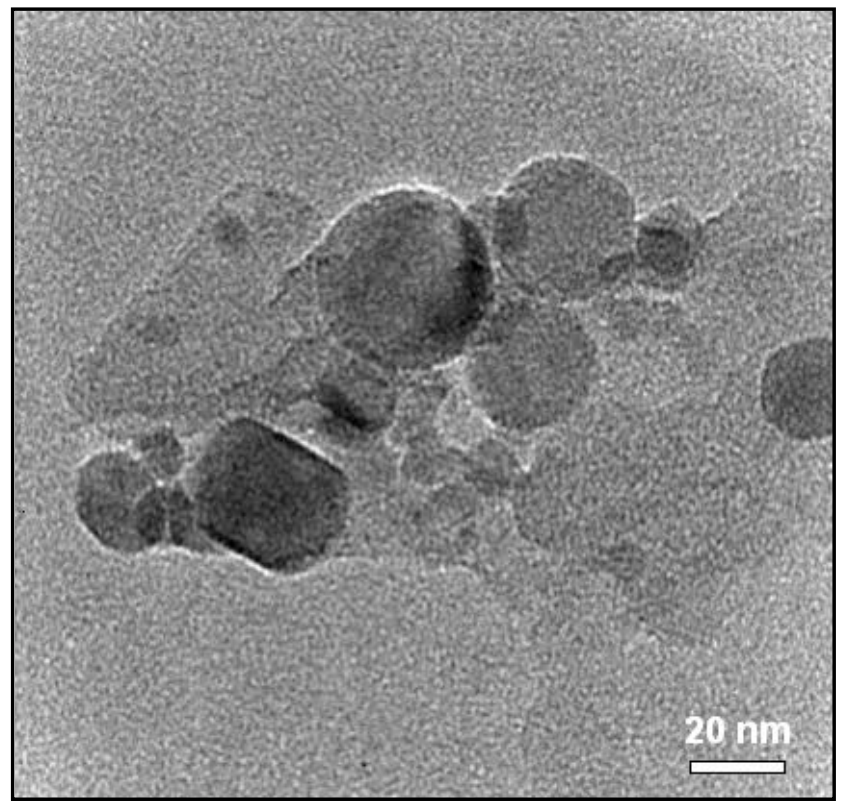

Figure 1. Micro photo of $\gamma \mathrm{Al}_{2} \mathrm{O}_{3}$ obtained by aluminium chloride thermo-hydrolysis

The produced material, then, is joint grinded in a planetary-type mill to the average size of 70-90 $\mathrm{nm}$. Figure 2 shows the size distribution after this process.

Both ways of polymer mixing have been studied. The first one is joint grinded in polymer dispersion and the second one being dry blended. The nature of interaction is supposed to be either physical or chemical. The polymer cements' hardening, from the physical point of view, includes a combination of two opposite processes, i.e. Portland cement clinker hydration and autohesion of polymer dispersion. On the one hand, a mineral-binding material may harden only in presence of water, and film formation occurs by drying. From the chemical point of view, the $\gamma \mathrm{Al}_{2} \mathrm{O}_{3}$ grains can be the centres of clinker minerals' crystallization. 


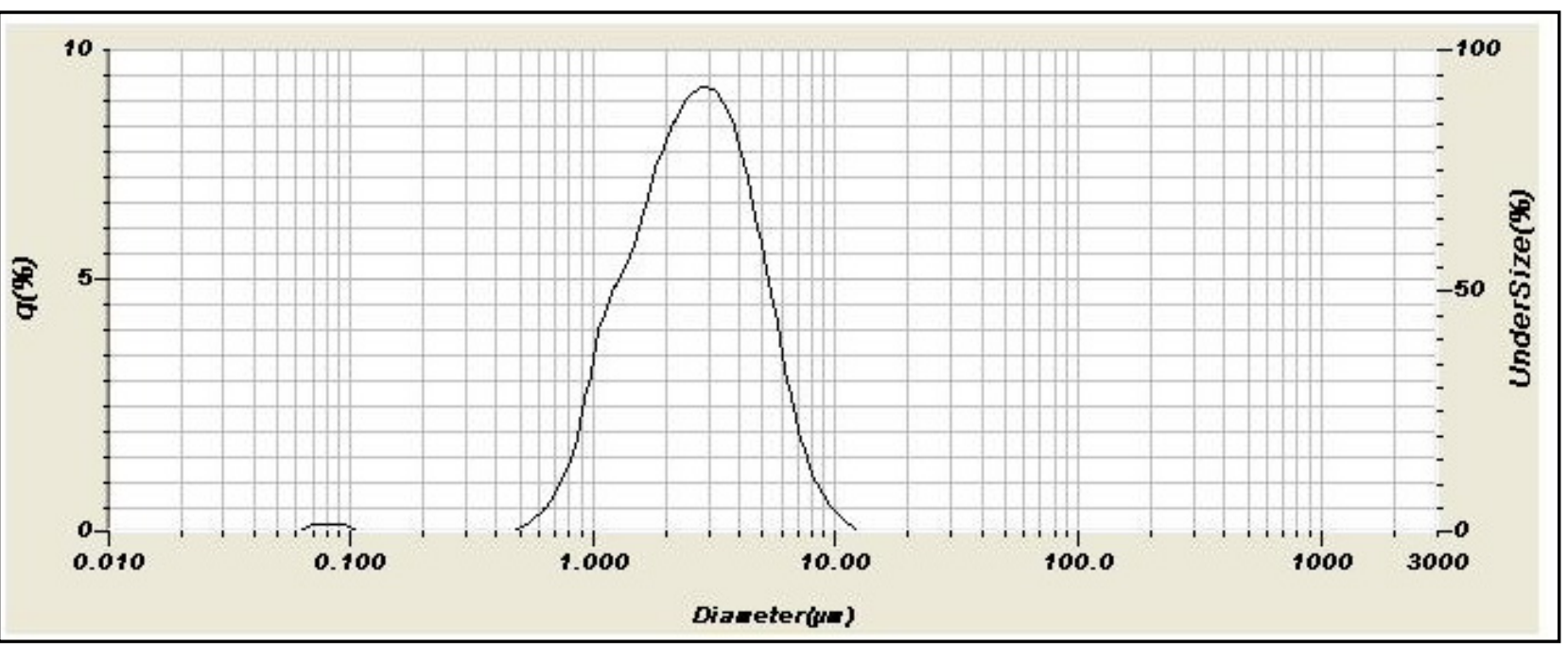

Figure 2. Size distribution of $\gamma \mathrm{Al}_{2} \mathrm{O}_{3}$ after joint grinding in a planetary mill

In this feasibility study by the Rogante Engineering Office (REO), specimens with different additive ratios, produced by DBM-URFU, have been considered for a SANS investigation. The chemical composition includes: ordinary Portland cement, redispersible dry polymer (vinyl acetate and vinyl versatate) and $\mathrm{Al}_{2} \mathrm{O}_{3}$, with different $\gamma$ $\mathrm{Al}_{2} \mathrm{O}_{3} /$ redispersible dry polymer ratios, the water/cement ratio remaining stable. These samples are usually submitted to the following tests: bending and compressive strength, water absorption and density.

Today PCC has wide applications in industry. Since these compositions possess increased bending strength, water and frost resistance, high adhesive properties, low abradability and porosity, they can be used as construction materials of high quality, such as coatings, plasters and insulation.

\subsection{Neutron Beam Techniques Applicable for This Investigation}

The most applicable NBT for the investigation of cements and, in particular, PCCs, are SANS, inelastic neutron scattering (INS), quasi-elastic neutron scattering (QENS), neutron radiography (NR), prompt gamma activation analysis (PGAA) and neutron diffraction (ND).

SANS accurately and completely characterises materials at the micro and nano levels, providing statistically precise information averaged over a macroscopic volume. Parameters relative to the scattering objects (defects) can be monitored, such as diameter, concentration, volume fraction and area of interface. SANS consents investigations of the fine-pore porosity without any drying or pre-treatment of specimens as requested by other techniques used to measure the porosity and the pore size distribution. Preliminary SANS curves indicate, in their first part, the object's size, and in the next part the object's shape. A main objective of a SANS experiment is to obtain the differential cross-section, containing all the information on the shape, size and interactions of the scattering bodies - assemblies of scattering centres - in the sample. Further treatment of the SANS data involves various functions. In this paper the SANS data got has been treated in order to recognize the influence of the different additives on the nanostructure of the investigated samples. The SANS data has been treated in order to find the peculiarities of the structure of interfaces inside the cement stone. It has been assumed that these polymers change the structure of concrete when the binding agent and water form cement stone which joins particles together to make a monolith. The cross sections in absolute units (per $\mathrm{cm}^{3}$ of sample's volume) are able to demonstrate a similar behavior. The cross section is described by a model function involving parameters that reflect the scattering abilities of nanoscale inhomogeneities in stone. The exhibit of a fractal character of these entities indicates the level of incoherent scattering mainly due in this case to water presence. This indicates in general that the eventual change in the interface quality (roughness). These parameters allow an understanding of how the introduction of small amounts of mineral and/or polymeric substances makes the interface more developed.

Concerning the sample preparation, SANS can handle various forms of samples, i.e. solid, liquid and gel. Sample preparation should be performed to obtain a sample appropriate for the experiment, as well as for the sample holder of the adopted SANS instrumentation. The sample's size should be adjusted to obtain good scattering, avoiding multiple scattering problems. It should be prepared furthermore for a proper neutron contrast.

The typical size of a sample suitable for a SANS measurement is a disc $1.0-2.0 \mathrm{~cm}$ in diameter having a thickness in the range $0.1-10 \mathrm{~mm}$. The thickness, in particular, depends on the constitutive material of the sample. An excessively thick sample, e.g., can produce multiple scattering, which can change the spectra, most particularly creating apparent scattering peaks. SANS, finally, requires high concentrations of the sample and huge sample homogeneity. The theoretical base of the SANS 
technique can be found in various references, e.g. [2, 11-14].

QENS is related to those inelastic processes of neutron scattering which are almost elastic. It allows the study of diffusion in solids, so it is ideal to study the reaction rate in hydrating cements. A QENS investigation of a hydrating cement paste, for instance, can directly assess the water fraction in the specimen that is chemically bound. If the reactions' stoichiometry is well enough understood, the ratio of chemically bound water to total water (bound water index) can be converted into the reaction degree and the measurements adopted to further investigate the reaction kinetics. INS can supply the same information as QENS, but with more information on the presence of different precipitates and on the vibration states of the system in the presence of these precipitates [15].

NR is the penetrating of a sample by a neutron beam, which is attenuated (according to the basic law of radiation attenuation) by the investigated material and by some light materials such as hydrogen, and lithium as detected by an imaging device. The obtained information is related to the material and structure inside the specimen. NR consents visualising and measuring the material's distribution within macroscopic volumes of the cement samples, as well as defining the water movement through the investigated cements. NR images of concrete structures are also helpful to validate conventional measurements. The theoretical base of the NR technique can be found in various references, e.g., $[2,12,16,17,18]$.

PGAA is based on the detection of characteristic prompt gamma photons that originate in $(\mathrm{n}, \gamma)$ nuclear reactions. The principles of this method have been well known for decades, nevertheless industrial applications are presently in development (see, e.g., [19, 20]). Every atomic nucleus, apart from ${ }^{4} \mathrm{He}$, may undergo a $(\mathrm{n}, \gamma)$ reaction with different probabilities. The energies of the emitted gamma photons are characteristic for each given isotope, while the intensities of the gamma peaks are proportional to the amount of a given isotope. This phenomenon allows the use of a quantitative elemental (isotopic) analysis method known as PGAA or PGNAA [21]. PGAA gives information on the sample as a whole: neutrons can penetrate the surface and lower layers of the material, so PGAA does not distinguish between the "bulk" and "surface" composition of a sample. The theoretical base of the PGAA technique can be found in various references, e.g. [2, 21-24].

$\mathrm{ND}$, complementarily to X-ray diffraction, is able to supply information on the crystalline phase of materials, including cements, providing data related to the specimen's bulk and helping the study of alterations and degradation processes. The theoretical basis of the ND technique can be found in various references, e.g. [2].

REO has developed special data treatments of neutron measurements, related to the described techniques, particularly for industrial applications.

\section{SANS Feasibility Analysis and Discussions}

Preliminary SANS measurements, carried out by REO at the Budapest Research Reactor on the samples described in Par. 2.1., at the neutron wavelengths of 1.201 and $0.412 \mathrm{~nm}$, have shown the suitability and the usefulness of adopting this technique.

Figure 3 shows a comparison of the cross sections for the cement sample without additives $\left(\sigma_{o}\right)$ and the cement samples with $\mathrm{Al}_{2} \mathrm{O}_{3}$, redispersible dry polymer and both substances.

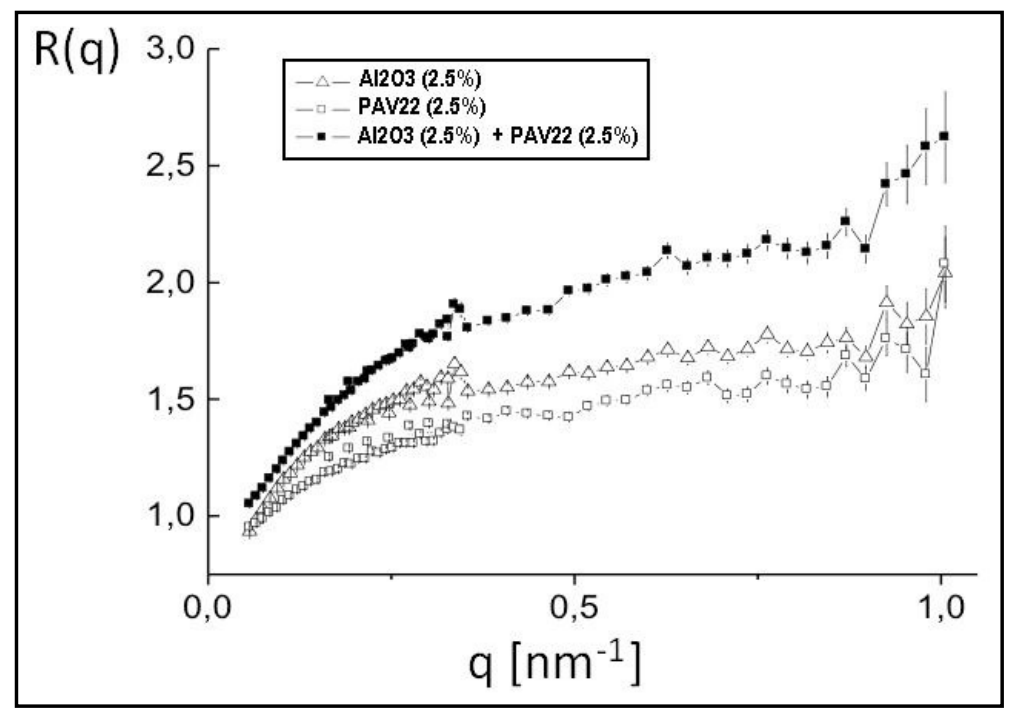

Figure 3. Cross sections for the $\mathrm{PCC}$ samples with $\mathrm{Al}_{2} \mathrm{O}_{3}$, redispersible dry polymer (PAV22) and both substances, normalized to the data of the original sample without additives: $R(q)=\sigma(q) / \sigma_{o}(q)$ vs. $q$ 
This comparison gives the following ratio of the cross sections:

$$
R(q)=\sigma(q) / \sigma_{o}(q) \approx 1.5-2
$$

at the momentum transfer $q \geq 0.3 \mathrm{~nm}^{-1}$.

The SANS data has been specifically treated to find the peculiarities of the interfaces' structure inside the cement stone. The main aim was to verify the assumption that these polymers change the concrete's structure when the binding agent and water forms the cement stone that joints the particles together to make a monolith. The modification of cement, by the results obtained, creates preferably a small-sized structure of stone. This should be treated as a positive factor for material functional properties (e.g., durability).

The main problems to be investigated by a full SANS analysis should include the following aspects. Research of the hydration processes through the contrast variation method, using light and heavy water to comprehend the mechanisms of water molecules association and their structuring in ceramics' matrix in the formation process of cement stone, as dependent on the addition of special entities (nano-particles, polymers and low molecular components modifying hydrogen bonds, such as salts, acids and bases). Also observation of kinetics linked with water reactions and nanoscale migration (localization) for short (seconds) and long (hours, days) times in connection with strength and hardness of cement stone at a microscopic level. Finally the study of porosity and the assessment of fractal dimension, size distribution and other characteristics (open, closed pores, cracks) at the scale of 1 to $100 \AA$ at large distances $10^{2}-10^{3} \AA$ using ultra-SANS.

The achievable results of a full SANS analysis, therefore, could supply information concerning, in particular, porosity, determination of fractal dimension, size distribution and other characteristics (open, closed pores, cracks). These results would contribute to studying the influence of adding polymer and $\gamma \mathrm{Al}_{2} \mathrm{O}_{3}$ to cement compositions so as to help monitor some important characteristics of the considered material.

The following examples concerning different other types of cements and their investigation by NBT are reported, as a state-of-the-art. NR was used to study cracks in concrete samples. Digital radiographs, obtained by the direct method with a gadolinium converter screen, consented to visualizing cracks, with better results in comparison to digital X-ray radiography [25]. A cement-based waste-form was investigated by $\mathrm{NR}$, to be characterised for radioactive wastes disposals. NR images were able to show the pore size distribution as well as the amount of cracking. The rate of the water penetration was measured by combining NR and conventional absorptivity techniques. In particularly it was evidenced that cracks can distribute water through the cement specimens [26]. $100 \times 100 \times 20 \mathrm{~mm}^{3}$ concrete specimens, made with a water-cement (ordinary Portland) ratio of 0.65 and 50 , were also investigated by NR. It was observed that water penetrates through the crack immediately after pouring, and its migration speed and distribution depends on the moisture condition in the concrete. Water behaviour in and around the crack, as well as water supply from the crack to the rebar were studied [27]. The concrete's natural drying process influences notably its features and performances (e.g., durability). Concrete specimens, wet cured for one day and covered on all the sides but one, were investigated by NR with the different aims of monitoring the water movement inside the material, quantifying the measured water content and porosity and comparing the results with conventional gravimetrical data [28]. The concrete's durability can be evaluated by assessing some characteristics such as permeability, porosity and absorptivity. A study was carried out, with the following purposes: to consider the NR ability to achieve quantitative data for porosity and absorptivity related to concrete, in comparison with the results from traditional methods; to analyse the effects that water to cement ratio and curing time have on the concrete's durability [29]. A cement standard used to qualify chemical laboratories of cement factories was analysed by PGAA, completing the data achieved during round robin tests of various laboratories using other methods such as classical analytical chemistry, atomic absorption spectroscopy, X-ray fluorescence spectroscopy and gravimetry. PGAA allowed also determining a few trace elements, which did not appear in the certification of the standard, and the results showed good agreement with the cement's reference values [24]. Neutron activation analysis was used to assess the concentration of trace elements normally present in concrete shielding (mainly in cement), accountable of high radioactivity of a NPP shielding after decommissioning.

Diverse cement specimens were irradiated with neutron beams and analysed by a $\gamma$-ray counting system. It was found that the radioactivity from certain elements $(\mathrm{Ce}, \mathrm{Co}, \mathrm{Cs}, \mathrm{Eu}$, $\mathrm{Fe}, \mathrm{Hf}, \mathrm{Sb}, \mathrm{Sc}, \mathrm{Ta}$ and $\mathrm{Tb}$ ) has a main role after a long cooling time or NPP decommissioning [30]. The radionuclide composition and distribution in high and regular density concrete specimens exposed to neutron and gamma irradiation as well as radioactive contamination was assessed. This supplied essential information on the management of decommissioning waste, the concrete's decontamination and the behaviour of radionuclides in cement-based engineered barriers [31]. Composition and microstructural changes of cement pastes when heating up to $620{ }^{\circ} \mathrm{C}$ and cooling subsequently, in different conditions, have been monitored by simultaneous ND data acquisition. High temperatures above the $300^{\circ} \mathrm{C}$, in fact, can involve alterations of the mechanical properties (e.g., compressive strength, elastic limit and fluency resistance). The analysis of the obtained ND patterns allowed identifying the main crystal phases such as portlandite, ettringite, calcite, lime, hydrated calcium silicate and larnite [32]. Quasi-elastic neutron scattering was used to evaluate the state of water in saturated type I Portland cement paste. The relative amount of frozen water with water/cement ratios of $0.3,0.4$ and 0.5 
were assessed with reference to a temperature ranging from $+3 \mathrm{C}$ to $-40{ }^{\circ} \mathrm{C}$. The amount of frozen water relative to the total water content was related to the water filled pore size predicted to be freezable at each temperature [33]. Since understanding and control of the cement hardening process is of great economic importance, ordinary Portland cement, hydrated with light and heavy water and mixed with specific precipitates adopted to condition radioactive waste, was investigated by inelastic neutron scattering. The considered samples were cementitious systems involving hydrated cement matrices prepared from anhydrous cement and fresh precipitate of calcium hydroxide, aluminium hydroxide, $\mathrm{NaSiO}_{2}$ and bentonite.

The obtained data consented to better comprehend the behaviour of $\mathrm{H}_{2} \mathrm{O}$ and $\mathrm{D}_{2} \mathrm{O}$ molecules in the material's structure and the influence of the additives to the general dynamics of the specimen. The cement matrix prepared with $\mathrm{D}_{2} \mathrm{O}$ turned out to be more stable than that prepared with $\mathrm{H}_{2} \mathrm{O}$ [15]. SANS and X-ray scattering techniques were adopted to assess the composition and solid density of the main binding reaction product of cement hydration, calcium-silicate-hydrate $(\mathrm{C}-\mathrm{S}-\mathrm{H})$ gel.

The study allowed determining the mean formula and the mass density of the nanoscale $\mathrm{C}-\mathrm{S}-\mathrm{H}$ gel particles in hydrating cement, as well as classifying water by its location, with implications for defining the chemically active $(\mathrm{C}-\mathrm{S}-\mathrm{H})$ surface area within cement and for forecasting the concrete's properties [34].

\section{Conclusion}

NBT are able to characterize in a non-destructive way cements, including dense cements and cement stones, allowing the obtaining of data complementary to such achievable by using traditional examination methods.

A preliminary SANS investigation of $\mathrm{PCC}$ samples made of Portland or aluminous cement with added $\gamma \mathrm{Al}_{2} \mathrm{O}_{3}$ and redispersible dry polymer has shown that the modification of cement by these additions generates preferably a small-sized structure of stone. This should be considered as a positive factor for the functional properties (e.g., durability) of the material. A full SANS study would supply, in this case, significant data on essential parameters connected with degradation, fracture and other phenomena, allowing also a more reliable lifetime assessments.

Various other works have been reported, to represent the state-of-the-art in the application of NBT for the study of PCC. This demonstrates the complementarity of the considered methods with conventional techniques. The results achieved by adopting NBT can be used to optimize performance and reliability to support and achieve a better final product quality.

\section{REFERENCES}

[1] T. V. Fursa, A. P. Surzhikov, K. Yu. Osipov. Development of an acoustoelectric method for determining the porosity of dielectric materials, Russian Journal of Nondestructive Testing, Vol. 43, No. 2, 95-99, 2006.

[2] M. Rogante. Applicazioni Industriali delle Tecniche Neutroniche, Proc. 1st. Italian Workshop for Industry "Industrial Applications of Neutron Techniques", Civitanova Marche, Italy, 40-120, 2008.

[3] M. Rogante, L. Rosta. Nanoscale characterisation by SANS and residual stresses determination by neutron diffraction related to materials and components of technological interest, Proc. SPIE 5824, Opto-Ireland 2005: Nanotechnology and Nanophotonics, Bellingham, WA 294-305, 2005.

[4] M. Puterman, W. Malorny. Some doubts and ideas on the microstructure formation of PCC, Proc. 9th Int. Congress on Polymers in Concrete - ICPIC 1998, Bologna, Italy, 165-178, 1998.

[5] I. Domanskaya, F. Kapustin, E. Mokhort, V. Oleynik. The main approaches of component selection for fine polymercement products and coatings, Proc. 15th Int. Conf. on Building Materials "Ibausil", Weimar, Germany, Vol. 2, 523-530, 2003.

[6] A. Dimmig. Chemical and Physical Effects on the Microstructure of PCC, 11th Int. Congress on Polymer in Concrete, IX.ICPIC, BAM, Berlin, 19-28, 2004.

[7] R. Wang, P. M. Wang, X. G. Li. Physical and mechanical properties of styrene-butadiene rubber emulsion modified cement mortars, Cement and Concrete Research, Vol. 35, No. 5, 900-906, 2005.

[8] V. Bhikshma, K. Jagannadha Rao, B. Balaji. An experimental study on behavior of polymer cement concrete, Asian Journal of Civil Engineering (Building and Housing), Vol. 11, No. 5, $563-573,2010$.

[9] N. N. Kruglitsky, G. P. Boyko. Physico-Chemical Mechanics of cement polymer compositions, Naukova Dumka, Kiev, 1981.

[10] Patent RU 2384522 C1: Method of obtaining oxide nanoparticles of metal. V. Vasiliev, A. Bazhenov, E. Vladimirova, V. Kozhevnikov, A. Nosov, E. Mohort, T. Chistyakova, Institute of solid state chemistry of the Ural branch of the Russian Academy of Sciences (RU), Published: 20.03.2010 Byull. № 8 .

[11] M. Rogante. Caratterizzazione, mediante scattering neutronico, di materiali e componenti per l'impiantistica nucleare ed industriale, $\mathrm{PhD}$ thesis, University of Bologna, Italy, 223, 1999.

[12] C. Williams, R. P. May, A. Guinier. Small-Angle Scattering of X-rays and Neutrons, Characterisation of Materials, "Materials Science and Technology", VCH Verlagsgesellschaft, Weinheim, Vol. 2B, 611-656, 1994.

[13] H. M. Rietveld. Line profiles of neutron powder-diffraction peaks for structure refinement, Acta Crystallographica, Vol. 22, 151-152, 1967.

[14] H. M. Rietveld. Profile refinement method for nuclear and magnetic structures, Journal of Applied Crystallography, Vol. 2, 65-71, 1969. 
[15] C. A. Dragolici, A. Radulescu, Gh. Rotarescu, F. Dragolici. Study of the structure and dynamics relaxation phenomena in complex disordered systems, resulting from hydration of the cement pastes, using the neutron scattering techniques, Romanian Reports in Physics, Vol. 62, No. 4, 791-800, 2010.

[16] M. Balaskó, M. Rogante. La radiografia neutronica al servizio dell'industria, Progettare, Vol. 273, 35-39, 2003.

[17] M. Balaskó, E. Sváb. Neutron Radiography in Research and Development, Nukleonica, Vol. 39, No. 1/2, 3-22, 1994.

[18] H. Berger. Neutron Radiography. Methods, Capabilities, and Applications, Elsevier, New York, 146, 1965.

[19] M. E. Heaton, M. Rogante, Zs. Kasztovszky, D. Denieffe. Prompt Gamma Activation Analysis of impurity and elemental stability for two SU-8 organic polymer samples having different solidification pre-treatment, The Open Inorganic Chemistry Journal, Vol. 3, 33-38, 2009.

[20] M. Rogante, L. Rosta, M. E. Heaton. Neutron beam measurement of industrial polymer materials for composition and bulk integrity, Measurements Science \& Technology, in print.

[21] M. Rogante. Neutroni per l'investigazione di componenti e materiali industriali, ICP, Vol. 2, 72-75, 2008.

[22] Zs. Révay, T. Belgya, Zs. Kasztovszky, J. L. Weil G. L. Molnár. Cold neutron PGAA facility at Budapest, Nuclear Instruments and Methods in Physics Research Section B: Beam Interactions with Materials and Atoms, Vol. 213, 385-388, 2004.

[23] Zs. Révay, G. L. Molnar, T. Belgya, Zs. Kasztovszky, R. B. Firestone. A new gamma-ray spectrum catalog and library for PGAA, Journal of Radioanalytical and Nuclear Chemistry, Vol. 248, No. 2, 395-399, 2001.

[24] Zs. Révay. Determining Elemental Composition Using Prompt $\gamma$ Activation Analysis, Analytical Chemistry, Vol. 81 6851-6859, 2009.

[25] R. Pugliesi, M. L. G. Andrade. Study of cracking in concrete by neutron radiography, Applied Radiation and Isotopes, Vol. 48, No. 3, 339-344, 1997.
[26] P. J. McGlinn, F. C. De Beer, L. P. Aldridge, M. J. Radebe, R. Nshimirimana, D. R. M. Brew, T. E. Payne, K. P. Olufson. Appraisal of a cementitious material for waste disposal: Neutron imaging studies of pore structure and sorptivity, Cement and Concrete Research, Vol. 40, No. 8, 1320-1326, 2010 .

[27] M. Kanematsu, I. Maruyama, T. Noguchi, H. Iikura, N. Tuchiya. Quantification of water penetration into concrete through cracks by neutron radiography, Nuclear Instruments and Methods in Physics Research Section A: Accelerators, Spectrometers, Detectors ans Associated Equipment, Vol. 605 , No. 1/2, 154-158, 2009.

[28] F. C. De Beer, W. J. Strydom, E. J. Griesel. The drying process of concrete: a neutron radiography study, Applied Radiation and Isotopes, Vol. 61, No. 4, 617-623, 2004.

[29] F. C. De Beer, J. J. Le Roux, E. P. Kearsley. Testing the durability of concrete with neutron radiography, Nuclear Instruments and Methods in Physics Research Section A: Accelerators, Spectrometers, Detectors and Associated Equipment, Vol. 542, No. 1/3, 226-231, 2005.

[30] M. E. Medhat, M. Fayez-Hassan. Elemental analysis of cement used for radiation shielding by instrumental neutron activation analysis, Nuclear Engineering and Design, Vol. 241, No. 6, 2138-2142, 2011.

[31] J. P. Krasznai. The radiochemical characterization of regularand high-density concrete from a decommissioned reactor, Waste Management, Vol. 13, No. 2, 131-140, 1993.

[32] M. Castellote, C. Alonso, C. Andrade, X. Turrillas, J. Campo. Composition and microstructural changes of cement pastes upon heating, as studied by neutron diffraction, Cement and Concrete Research, Vol. 34, 1633-1644, 2004.

[33] D. L. Gress, T. El-Korchi, R. A. Livingston, D. A. Neumann, J. J. Rush. Using Quasielastic Neutron Scattering Techniques to Quantify Freezable Water in Portland Cement Paste, MRS Proceedings, Vol. 36, 376-493, 1994.

[34] A. J. Allen, J. J. Thomas, H. M. Jennings, Composition and density of nanoscale calcium-silicate-hydrate in cement, Nature Materials, Vol. 6, 311-316, 2007. 